\title{
Cellular hyper-excitability caused by mutations that alter the activation process of voltage-gated sodium channels
}

\author{
Mohamed-Yassine Amarouch ${ }^{1 *}$ and Hugues Abriel ${ }^{2 *}$ \\ Materials, Natural Substances, Environment and Modeling Laboratory, Multidisciplinary Faculty of Taza, University of Sidi Mohamed Ben Abdellah-Fes, Taza, \\ Morocco \\ ${ }^{2}$ Department of Clinical Research, University of Bern, Bern, Switzerland
}

\section{Edited by:}

Maria Cristina D'Adamo, University of Perugia, Italy

Reviewed by:

Flavien Charpentier, INSERM,

France

Elena V. Zaklyazminskaya, Petrovsky

Russian Research Centre of

Surgery, Russia

\section{*Correspondence:}

Mohamed-Yassine Amarouch, Materials, Natural Substances,

Environment and Modeling

Laboratory, Multidisciplinary Faculty of Taza, University of Sidi Mohamed

Ben Abdellah-Fes, BP 1223

Taza-Gare, Taza, Morocco

e-mail: amarouch.my@gmail.com;

Hugues Abriel, Department of

Clinical Research, University of

Bern, Murtenstrasse 35, 3010 Bern,

Switzerland

e-mail: hugues.abriel@dkf.unibe.ch
Voltage-gated sodium channels $\left(\mathrm{Na}_{\mathrm{v}}\right)$ are widely expressed as macro-molecular complexes in both excitable and non-excitable tissues. In excitable tissues, the upstroke of the action potential is the result of the passage of a large and rapid influx of sodium ions through these channels. Nav dysfunction has been associated with an increasingly wide range of neurological, muscular and cardiac disorders. The purpose of this review is to summarize the recently identified sodium channel mutations that are linked to hyper-excitability phenotypes and associated with the alteration of the activation process of voltage gated sodium channels. Indeed, several clinical manifestations that demonstrate an alteration of tissue excitability were recently shown to be strongly associated with the presence of mutations that affect the activation process of the $\mathrm{Na}_{\mathrm{v}}$. These emerging genotype-phenotype correlations have expanded the clinical spectrum of sodium channelopathies to include disorders which feature a hyper-excitability phenotype that may or may not be associated with a cardiomyopathy. The p.I141V mutation in SCN4A and SCN5A, as well as its homologous p.1136V mutation in SCN9A, are interesting examples of mutations that have been linked to inherited hyperexcitability myotonia, exercise-induced polymorphic ventricular arrhythmias and erythromelalgia, respectively. Regardless of which sodium channel isoform is investigated, the substitution of the isoleucine to valine in the locus 141 induces similar modifications in the biophysical properties of the $\mathrm{Na}_{v}$ by shifting the voltage-dependence of steady state activation toward more negative potentials.

Keywords: $\mathrm{Na}_{\mathrm{v}} 1.5-\mathrm{I141 \textrm {V }}$, hyper-excitability, dilated cardiomyopathy, myotonia, erythromelalgia

\section{INTRODUCTION}

In excitable tissues, action potential initiation and propagation are the result of the passage of a large and rapid influx of sodium ions through the voltage-gated sodium channels $\left(\mathrm{Na}_{\mathrm{V}}\right)$. These channels consist of highly processed $\alpha$-subunits that are present as nine different isoforms (Goldin et al., 2000). The $\alpha$-subunit of the sodium channel is composed of four homologous domains (Noda et al., 1984). Each of these domains contains six $\alpha$-helical transmembrane segments (S1-S6). The first four segments (S1S4) comprise the voltage-sensing domain (VSD), and the last two segments (S5 and S6) form the pore of the channel when assembled in a tetrameric configuration (Figure 1) (Payandeh et al., 2011). $\mathrm{Na}_{V}$ dysfunction causes multiple inherited diseases, formerly known as channelopathies. Rare mutations and common variants in genes encoding the $\alpha$-subunits have been associated with several familial forms of neurological, muscular and cardiac disorders (Cheng et al., 2008; Petitprez et al., 2008; Probst et al., 2009; Meisler et al., 2010; Abriel and Zaklyazminskaya, 2013; Bezzina et al., 2013; Liu et al., 2014; Swan et al., 2014).

The $\mathrm{Na}_{V}$ have been shown to be part of multi-protein complexes that are located in different cellular compartments. In addition to the $\mathrm{Na}_{\mathrm{v}} \alpha$-subunits, these complexes have $\mathrm{Na}_{\mathrm{v}}$-interacting proteins that regulate channel expression and function (Abriel, 2010; Laedermann et al., 2013a,b). Similar to that described for the sodium channel $\alpha$-subunits, mutation in genes encoding the $\mathrm{Na}_{\mathrm{v}}$-interacting proteins have been linked to the occurrence of several inherited diseases (Abriel, 2010; Catterall, 2014).

Several naturally occurring mutations that affect the activation process of the voltage-gated sodium channel have been recently associated with alterations of neuronal, muscular and cardiac excitabilities (Cheng et al., 2008; Petitprez et al., 2008; Laurent et al., 2012; Mann et al., 2012; Beckermann et al., 2014). The p.I141V mutation in SCN4A and SCN5A, as well as its homologous mutation p.I136V in $S C N 9 A$, are interesting examples of substitutions that lead to the occurrence of inherited hyper-excitability phenotypes. Depending on the sodium channel isoform, the I/V substitution is associated with familial forms of myotonia, exercise-induced polymorphic ventricular arrhythmias or erythromelalgia (Lee et al., 2007; Cheng et al., 2008; Petitprez et al., 2008; Swan et al., 2014).

The purpose of this review is to summarize the recently identified sodium channel mutations that are linked to cardiac hyperexcitability phenotypes and associated with the alteration of the activation process of voltage gated sodium channels. 


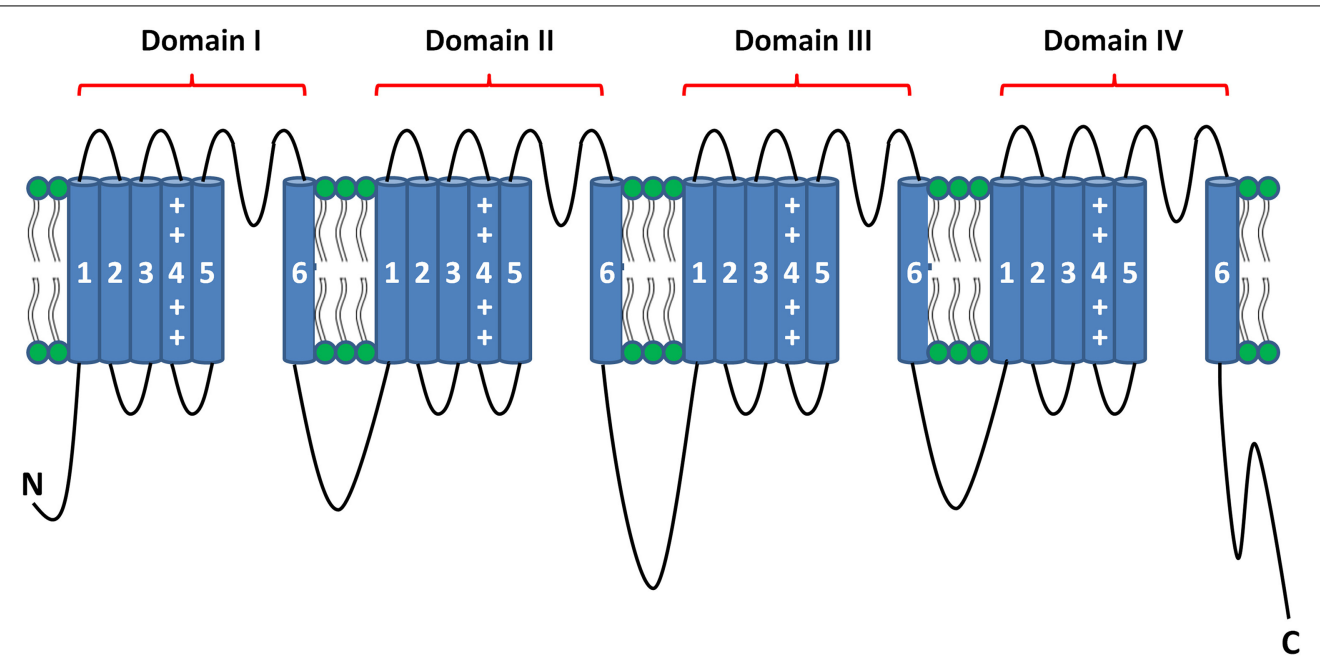

FIGURE 1 | Topology of the pore-forming $\alpha$-subunit of voltage gated sodium channels.

\section{CELLULAR EXCITABILITY AND VOLTAGE GATED SODIUM CHANNELS}

In nervous, muscular, and cardiac tissues, $\mathrm{I}_{\mathrm{Na}}$ influx through the $\mathrm{Na}_{\mathrm{v}}$ channels is the major depolarizing current and, thus, underlies cellular excitability. Mutations that affect the function of these $\mathrm{Na}_{\mathrm{v}}$ channels have been shown to modify the excitability pattern of these tissues. As an example, loss of function mutations of $\mathrm{Na}_{\mathrm{v}} 1.5$, leading to a decreased excitability of cardiac cells (hypo-excitability), slow the cardiac conduction velocity (Amin et al., 2010). On the opposite, gain of function mutations of these channels may reduce the excitation threshold and increase the conduction velocity leading to an increased cardiac excitability (hyper-excitability) (Swan et al., 2014). In the present review article, we focus on mutations that are linked with cellular hyper-excitability phenotypes.

\section{CARDIAC HYPER-EXCITABILITY PHENOTYPES RELATED TO AN ALTERED ACTIVATION PROCESS OF Nav1.5 THE CARDIAC SODIUM CHANNEL, Nav1.5}

$\mathrm{Na}_{\mathrm{V}} 1.5$ is the main sodium channel isoform expressed in cardiac cells (Yu and Catterall, 2003). Other $\mathrm{Na}_{\mathrm{v}} \alpha$-subunits, such as $\mathrm{Na}_{\mathrm{v}} 1.1,1.3,1.6$, and 1.8, are also present in the heart (Maier et al., 2004; Yang et al., 2012), and are mainly localized on the cardiomyocytes T-tubules or in the intracardiac neurons involved in neural control of the heart (Maier et al., 2002, 2004). These "non-cardiac" channels contribute to the conduction of a small proportion of the cardiac sodium current (Maier et al., 2002, 2004).

As aforementioned, the cardiac sodium channel is a multiprotein complex in which auxiliary proteins (i.e., $\beta$ subunits) interact with the $\alpha$-subunit, $\mathrm{Na}_{\mathrm{v}} 1.5$, to regulate its biology and function (Abriel, 2010). Some of these proteins, which are localized in specific regions of cardiac cells, have been shown to interact with the same regulatory domain of $\mathrm{Na}_{\mathrm{v}} 1.5$ (Abriel, 2010; Shy et al., 2013). As demonstrated by Shy and colleagues (Shy et al., 2014), the $\mathrm{Na}_{\mathrm{v}} 1.5$ channels are expressed as at least two distinct functional pools that are localized at the intercalated discs and the lateral membranes of the cardiomyocyte (Shy et al., 2014).

\section{DILATED CARDIOMYOPATHY AND ION CHANNEL DYSFUNCTION}

Dilated cardiomyopathy (DCM) is a cardiac structural disease characterized by decreased systolic function and ventricular dilatation. Inherited forms of this structural abnormality have been mainly linked to mutations in genes coding for cytoskeletal proteins (Haas et al., 2014). DCM has also been associated with mutations that affect $\mathrm{Na}_{\mathrm{v}} 1.5$ function, providing support to the argument that DCM could be considered as one of the phenotypes of cardiac sodium channelopathy (McNair et al., 2004; Olson et al., 2005; Ge et al., 2008; Nguyen et al., 2008; Morales et al., 2010; Laurent et al., 2012; Mann et al., 2012; Beckermann et al., 2014; Haas et al., 2014). The identified mutations appear to be preferentially localized in the VSD region of $\mathrm{Na}_{\mathrm{v}} 1.5$, and induce a loss or gain of function by affecting the voltage-dependencies of steady state activation and/or inactivation (McNair et al., 2004; Ge et al., 2008; Nguyen et al., 2008; Laurent et al., 2012; Mann et al., 2012; Beckermann et al., 2014). The sodium currents generated by some of these mutants have larger sodium window current peaks that are shifted toward more negative potentials (Nguyen et al., 2008; Laurent et al., 2012; Mann et al., 2012; Beckermann et al., 2014). In addition, Gosselin-Badaroudine and colleagues (GosselinBadaroudine et al., 2012) demonstrated that the R219H mutation in $\mathrm{Na}_{\mathrm{v}} 1.5$ causes a proton leak current, suggesting that this mutation induces intracellular acidification which may contribute to the DCM phenotype (Gosselin-Badaroudine et al., 2012).

The majority of studies that link the SCN5A gene to the occurrence of DCM demonstrate that this phenotype is usually associated with alterations in cardiac excitability (McNair et al., 2004; Ge et al., 2008; Nguyen et al., 2008; Gosselin-Badaroudine et al., 2012; Laurent et al., 2012; Mann et al., 2012; Shen et al., 2013; Beckermann et al., 2014). This observation raises several questions about the real origin of the observed structural defects. Are they a direct consequence of alterations in $\mathrm{Na}_{\mathrm{v}} 1.5$ function, or 
a result of pre-existing electrical arrhythmias? In some studies, the results of pharmacological therapy support the second hypothesis. Laurent et al (Laurent et al., 2012) and Mann et al (Mann et al., 2012) demonstrated improvement in cardiac function using the sodium channel-blocking properties of some anti-arrhythmic drugs, such as amiodarone, flecainide, and quinidine (Laurent et al., 2012; Mann et al., 2012).

These observations suggest that the association between $\mathrm{Na}_{\mathrm{v}} 1.5$ mutations and DCM is multifactorial. Some of the known involved factors are the existence of long-standing arrhythmias, the alteration of sodium channel function, the genetic background of the patient, and the presence of structural abnormalities (McNair et al., 2004; Ge et al., 2008; Nguyen et al., 2008; Cheng et al., 2010; Gosselin-Badaroudine et al., 2012; Laurent et al., 2012; Mann et al., 2012; Shen et al., 2013; Beckermann et al., 2014).

\section{CARDIAC HYPER-EXCITABILITY PHENOTYPES ASSOCIATED WITH Nav1.5 VOLTAGE SENSOR MUTATIONS}

Several studies (Olson et al., 2005; Laurent et al., 2012; Mann et al., 2012; Nair et al., 2012; Beckermann et al., 2014) have recently reported a new SCN5A-dependent clinical presentation characterized by an alteration in tissue excitability associated with DCM. All of the related SCN5A mutations (p.R814W, p.R222Q, p.R219H, and p.R225P) neutralize arginine residues that are localized in the S4 segment of domain I and II (Olson et al., 2005; Laurent et al., 2012; Mann et al., 2012; Nair et al., 2012; Beckermann et al., 2014). The functional consequences of these substitutions is either the alteration of $\mathrm{Na}_{\mathrm{v}} 1.5$ gating (Figure 2) (Olson et al., 2005; Laurent et al., 2012; Mann et al., 2012; Nair et al., 2012; Beckermann et al., 2014) or the induction of a pH-dependent inward $\mathrm{H}^{+}$current (Gosselin-Badaroudine et al., 2012).

The p.R814W substitution was the first mutation linked to the neutralization of an arginine in the $\mathrm{S} 4$ segment of $\mathrm{Na}_{\mathrm{v}} 1.5$. This mutation was associated with the occurrence of cardiac hyperexcitability and DCM (Olson et al., 2005). When compared to the WT condition, the $\mathrm{Na}_{\mathrm{v}} 1.5-\mathrm{R} 814 \mathrm{~W}$ mutant negatively shifted the voltage dependence of activation, slowed activation kinetics and increased the sodium window current (Nguyen et al., 2008).
Similar biophysical modifications of $\mathrm{Na}_{\mathrm{v}} 1.5$ were observed for the p.R222Q mutation. This mutation shifted the voltage dependence of activation toward more negative potentials and hastened the activation kinetics. The voltage dependence of inactivation, when combined with the activation shift, increased and shifted the sodium window current toward more negative potentials (Laurent et al., 2012; Mann et al., 2012; Nair et al., 2012). The clinical phenotypes associated with the p.R222Q substitution were variable. The observed phenotypes included the occurrence of peripartum DCM, arrhythmic DCM, escape capture bigeminy, and multifocal ectopic Purkinje-related premature contractions associated with DCM (Olson et al., 2005; Morales et al., 2010; Laurent et al., 2012; Mann et al., 2012; Nair et al., 2012).

An original mechanism linking the neutralization of S4 arginine residues with the occurrence of cardiac hyper-excitability has been described for the p.R219H mutation (Gosselin-Badaroudine et al., 2012). The functional characterization of this mutation by Chahine et al suggested that the presence of the p.R219H mutation may induce intracellular acidification by creating a $\mathrm{pH}$ dependent inward proton current, thus favoring the development of DCM and cardiac arrhythmias (Gosselin-Badaroudine et al., 2012).

Another $\mathrm{Na}_{\mathrm{V}} 1.5 \mathrm{VSD}$ arginine mutation, p.R225P, was recently identified in a boy with a prenatal arrhythmia and impaired cardiac contractility, followed by postnatal multifocal ventricular ectopy (Beckermann et al., 2014). This mutation affects the activation and inactivation processes, resulting in an increased and hyperpolarized sodium window current. The authors suggested that these biophysical modifications may lead to an aberrant sodium influx at potential ranges that are close to the resting membrane potential of cardiac cells, and thus may modify the excitability of cardiomyocytes (Beckermann et al., 2014).

\section{EXERCISE-INDUCED POLYMORPHIC VENTRICULAR ARRHYTHMIAS}

A clinical and genetic study of a large multigenerational Finnish family recently demonstrated an inherited form of exerciseinduced polymorphic ventricular arrhythmia caused by a newly identified SCN5A mutation, p.I141V (Swan et al., 2014). This mutation is located in a highly conserved region of the $\mathrm{Na}_{\mathrm{v}} 1.5$ channel domain I S1 transmembrane segment. The p.I141V

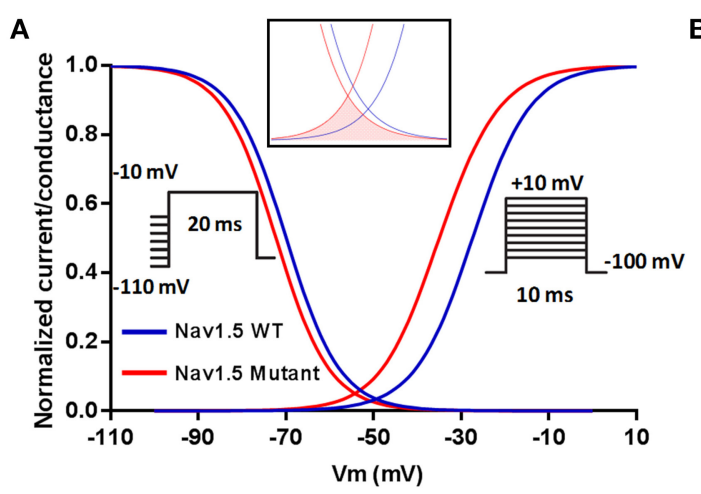

B

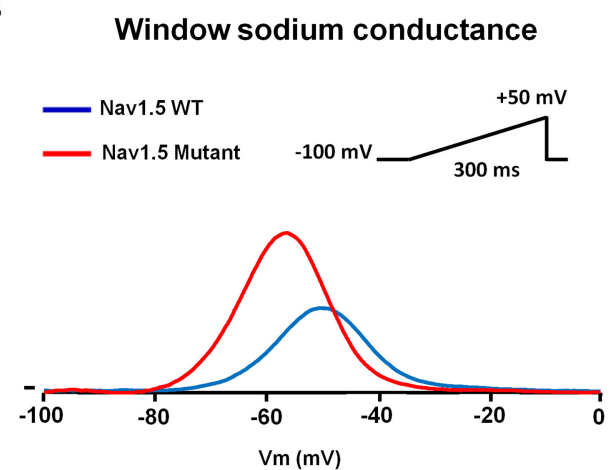

FIGURE 2 | Schematic representation of the shared mechanism of $\mathrm{Na}_{\mathbf{v}} \mathbf{1 . 5}$ mutations associated with cardiac hyper-excitability. Negative shift of the voltage dependence of activation (A) leading to a negative shift of the sodium window conductance (B) 


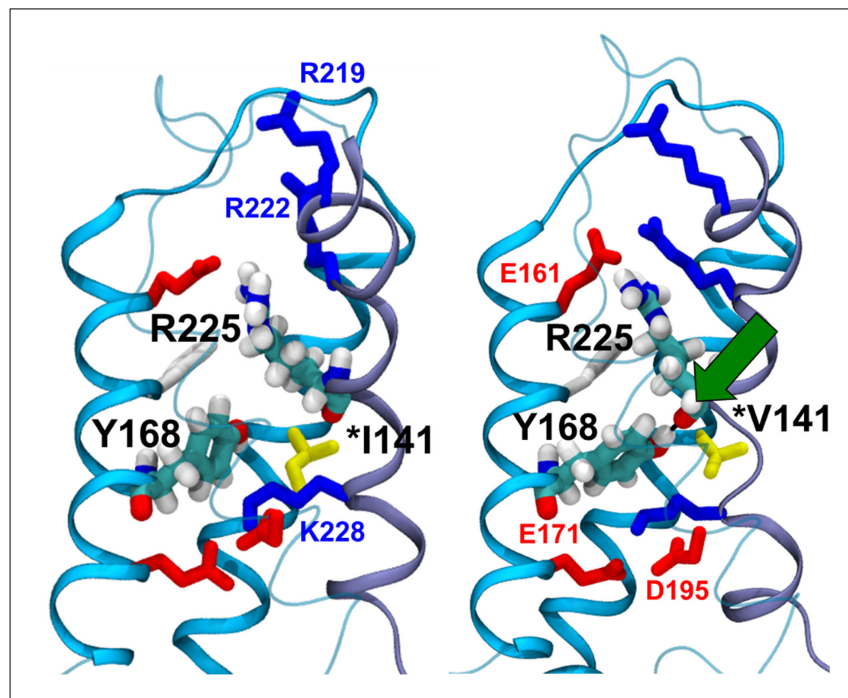

FIGURE 3 | Molecular dynamics simulation of the WT (left panel) and the p.I141V mutants (right panel) of $\mathrm{Na}_{\mathbf{v}} \mathbf{1 . 4}$ channel. In the presence of the p.I141V mutation, the model predicted the formation of a hydrogen bond (Green arrow) between the S2-Y168 and S4-R225 residues, thus stabilizing the open confirmation of the channel; (From Amarouch et al., 2014).

mutation shifted the voltage dependence of steady state activation toward more negative potentials. The p.I141V window current exhibited a larger peak which was shifted toward more negative potentials as compared to the WT (Figure 2). Computer modeling of the biophysical modifications induced by the p.I141V mutation, however, suggested a reduced excitation threshold for action potential generation in the presence of this mutation as compared to the WT.

The crystal structure of the bacterial channel $\mathrm{Na}_{v} \mathrm{Ab}$, published by the Catterall's group, shows close proximity between the isoleucine 141 residue of the S1 segment and arginines that are located in the S4 segment (Payandeh et al., 2011). Based on these observations, we hypothesized that the p.I141V substitution stabilizes the open conformation of the $\mathrm{Na}_{V}$ by modifying or creating new interactions between these specific segments (Amarouch et al., 2014). Molecular dynamic simulations, using the $\mathrm{Na}_{\mathrm{v}} 1.4$ model, predicted the formation of a hydrogen bond between the Y168-S2 and the R225-S4 residues in the presence of the p.I141V mutation on S1 (Figure 3). Single and double mutants, p.Y168F and p.I141V-Y168F, were generated in order to test these predictions in $\mathrm{Na}_{\mathrm{v}}$ 1.5. The functional analyses of these mutants demonstrated the abolition of the functional effects of the p.I141V mutation in the double mutant, consistent with the formation of a specific interaction between Y168-S2 and R225S4 (Figure 4). The single p.Y168F mutation positively shifted the activation curve, suggesting a compensatory role of these residues on the stability of the voltage-sensing domain.

\section{MUSCULAR HYPER-EXCITABILITY PHENOTYPES RELATED TO AN ALTERED ACTIVATION PROCESS OF Nav1.4-EXAMPLE OF MYOTONIA}

The skeletal voltage-gated sodium channel $\mathrm{Na}_{\mathrm{v}} 1.4$, encoded by the SCN4A gene, is responsible for the initiation of the action potential in muscle fibers, resulting in muscle contraction. Similar to that described for the cardiac sodium channel, the $\mathrm{Na}_{\mathrm{v}} 1.4$ $\alpha$-subunit is regulated by several proteins, i.e., the $\beta 1$ subunit that modifies kinetics and gating (Isom, 2001). Similar to the $\mathrm{Na}_{\mathrm{v}} 1.5$ channel, $\mathrm{Na}_{\mathrm{v}} 1.4$ is a large protein composed of four homologous domains (I-IV), each containing six transmembrane helices (S1-S6) (Figure 1). Mutations in the SCN4A gene have been associated with altered excitability of skeletal muscle (Jurkat-Rott et al., 2010). The majority of the mutations in $\mathrm{Na}_{\mathrm{v}} 1.4$ were found in the voltage sensor segments S4, the S4-S5 linkers, or in the pore forming segments S5-S6 (Jurkat-Rott et al., 2010). They were found to induce both a loss or gain of function. Gain of function effect has been described to be more frequent (Sokolov et al., 2007; Petitprez et al., 2008; Jurkat-Rott et al., 2010; Corrochano et al., 2014).

Myotonia is one example of skeletal muscle hyper-excitability in which a voluntary contraction or electromechanical stimulation can provoke trains of repetitive action potentials. This causes a delay in relaxation after muscle contraction. This phenotype has been associated with several SCN4A mutations that affect the activation and the slow inactivation processes of $\mathrm{Na}_{\mathrm{v}} 1.4$ (Petitprez et al., 2008; Jurkat-Rott et al., 2010; Kokunai et al., 2012; Yoshinaga et al., 2012; Corrochano et al., 2014). Among these SCN4A mutants, the substitution of isoleucine to valine in S1-DI and S1-DII affect the biophysical properties of $\mathrm{Na}_{\mathrm{V}} 1.4$ similar to the aforementioned example (Wagner et al., 1997; Petitprez et al., 2008). In vitro characterization of the p.I141V and p.I588V mutants demonstrated a negative shift of the voltage dependence of activation in the presence of these mutants (Wagner et al., 1997; Petitprez et al., 2008). In vivo characterization of p.I588V knockin mice demonstrated that these mice suffered from unprovoked intermittent hind-limb immobility attacks. The mice were not able to move their hind-limbs, confirming the implication of this mutation in the occurrence of myotonia (Corrochano et al., 2014).

\section{NEURONAL HYPER-EXCITABILITY PHENOTYPES RELATED TO AN ALTERED ACTIVATION PROCESS OF} Nav1.7-EXAMPLE OF ERYTHROMELALGIA

The $\mathrm{Na}_{\mathrm{V}} 1.7$ channel is one of the neuronal isoforms of voltage gated sodium channels. It is preferentially expressed in the nociceptive dorsal root ganglia and sympathetic ganglia, and may play an important role in nociception (Sangameswaran et al., 1997; Toledo-Aral et al., 1997; Cummins et al., 1998; Rush et al., 2007). Both gain and loss of function mutations of the SCN9A gene, which encodes the $\mathrm{Na}_{\mathrm{v}} 1.7 \alpha$-subunit, have been associated with pain syndromes, including erythromelalgia (Cox et al., 2006; Dib-Hajj et al., 2007).

Inherited erythromelalgia is a rare disorder characterized by recurrent episodes of pain associated with redness and swelling in various parts of the body, particularly the hands and the feet (Drenth and Michiels, 1990). Standing, exercise, or local exposure to heat can induce the symptoms in affected patients. Among the described $\mathrm{Na}_{\mathrm{v}} 1.7$ gain of function mutations that are associated with inherited erythromelalgia (Dib-Hajj et al., 2007; Cheng et al., 2008, 2011; Cregg et al., 2013; Estacion et al., 2013; Vasylyev et al., 2014), the isoleucine to valine substitution (as that described for the cardiac and muscular disorders) was found in a Taiwanese 


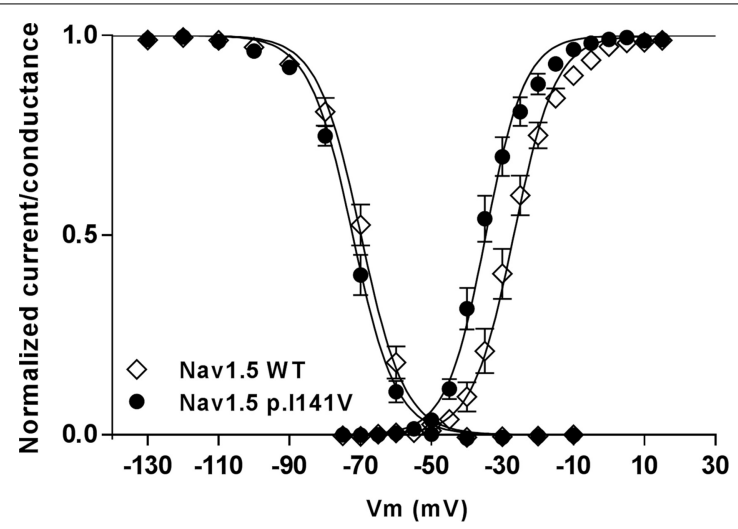

FIGURE 4 | The functional effect of the p.I141V mutation on the steady-state of activation and inactivation processes of $\mathrm{Na}_{\mathbf{v}} \mathbf{1 . 5}$ channel (left panel). The presence of this mutation induces a negative shift of the

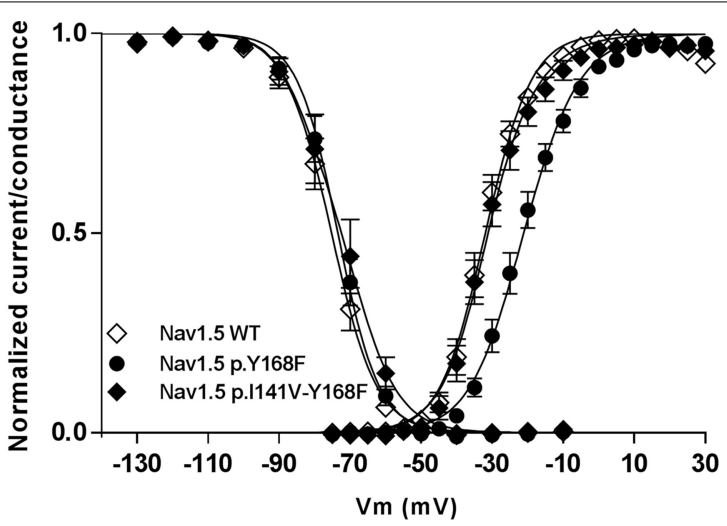

voltage dependence of activation. However, this effect was abolished in the presence of the p.Y168F substitution (right panel); (From Amarouch et al., 2014). family with the characteristic features of erythromelalgia. Lee et al identified the implicated p.I136V mutation in the $\mathrm{Na}_{\mathrm{v}} 1.7$ channel (Lee et al., 2007), which exhibited similar biophysical modifications to the $\mathrm{Na}_{\mathrm{v}} 1.4-\mathrm{I} 141 \mathrm{~V}$ and $\mathrm{Na}_{\mathrm{v}} 1.5-\mathrm{I} 141 \mathrm{~V}$ mutants. The p.I136V mutant shifted the voltage dependence of activation toward more negative potentials, leading to an increase and shift of the sodium window current (Cheng et al., 2008).

\section{CONCLUSION}

In this review, the comparison between several $N a_{\mathrm{v}}$ mutants that have been linked to cardiac, muscular, and neuronal hyperexcitability phenotypes has revealed: (i) a focused localization of these mutants on the VSD domain, particularly on the S4 arginine residues for cardiac disorders, (ii) an abnormal voltage dependence of activation as a shared biophysical mechanism of the clinical manifestations, and (iii) the functional importance of some highly conserved residues, notably isoleucine 141 for $\mathrm{Na}_{\mathrm{v}} 1.4$ and $\mathrm{Na}_{\mathrm{v}} 1.5$, and the homologous isoleucine 136 in $\mathrm{Na}_{\mathrm{v}} 1.7$.

\section{ACKNOWLEDGMENTS}

We thank Dr. A. Felley for her comments on this manuscript. The group of HA is supported by a grant of the Swiss National Science Foundation 310030_14060 and from the European Community's Seventh Framework Programme FP7/2007-2013 under grant agreement no. HEALTH-F2-2009-241526, EUTrigTreat.

\section{REFERENCES}

Abriel, H. (2010). Cardiac sodium channel $\mathrm{Na}(\mathrm{v}) 1.5$ and interacting proteins: physiology and pathophysiology. J. Mol. Cell. Cardiol. 48, 2-11. doi: 10.1016/j.yjmcc.2009.08.025

Abriel, H., and Zaklyazminskaya, E. V. (2013). Cardiac channelopathies: genetic and molecular mechanisms. Gene 517, 1-11. doi: 10.1016/j.gene.2012.12.061

Amarouch, M.-Y., Kasimova, M. A., Tarek, M., and Abriel, H. (2014). Functional interaction between S1 and S4 segments in voltage-gated sodium channels revealed by human channelopathies. Channels 8, 414-420. doi: 10.4161/19336950.2014.958922

Amin, A. S., Asghari-Roodsari, A., and Tan, H. L. (2010). Cardiac sodium channelopathies. Pflugers Arch. 460, 223-237. doi: 10.1007/s00424-009-0761-0
Beckermann, T. M., McLeod, K., Murday, V., Potet, F., and George, A. L. Jr. (2014). Novel SCN5A mutation in amiodarone-responsive multifocal ventricular ectopy-associated cardiomyopathy. Heart Rhythm 11, 1446-1453. doi: 10.1016/j.hrthm.2014.04.042

Bezzina, C. R., Barc, J., Mizusawa, Y., Remme, C. A., Gourraud, J. B., Simonet, F., et al. (2013). Common variants at SCN5A-SCN10A and HEY2 are associated with Brugada syndrome, a rare disease with high risk of sudden cardiac death. Nat. Genet. 45, 1044-1049. doi: 10.1038/ ng. 2712

Catterall, W. A. (2014). Sodium channels, inherited epilepsy, and antiepileptic drugs. Annu. Rev. Pharmacol. Toxicol. 54, 317-338. doi: 10.1146/annurevpharmtox-011112-140232

Cheng, J., Morales, A., Siegfried, J. D., Li, D., Norton, N., Song, J., et al. (2010). SCN5A rare variants in familial dilated cardiomyopathy decrease peak sodium current depending on the common polymorphism H558R and common splice variant Q1077del. Clin. Transl. Sci. 3, 287-294. doi: 10.1111/j.17528062.2010.00249.x

Cheng, X., Dib-Hajj, S. D., Tyrrell, L., Te Morsche, R. H., Drenth, J. P., and Waxman, S. G. (2011). Deletion mutation of sodium channel $\mathrm{Na}(\mathrm{V}) 1.7$ in inherited erythromelalgia: enhanced slow inactivation modulates dorsal root ganglion neuron hyperexcitability. Brain 134(Pt 7), 1972-1986. doi: 10.1093/brain/ awr143

Cheng, X., Dib-Haji, S. D., Tyrrell, L., and Waxman, S. G. (2008). Mutation I136V alters electrophysiological properties of the $\mathrm{Na}(\mathrm{v}) 1.7$ channel in a family with onset of erythromelalgia in the second decade. Mol. Pain 4:1. doi: 10.1186/17448069-4-1

Corrochano, S., Männikkö, R., Joyce, P. I., McGoldrick, P., Wettstein, J., Lassi, G., et al. (2014). Novel mutations in human and mouse SCN4A implicate AMPK in myotonia and periodic paralysis. Brain 137, 3171-3185. doi: 10.1093/brain/ awu292

Cox, J. J., Reimann, F., Nicholas, A. K., Thornton, G., Roberts, E., Springell, K., et al. (2006). An SCN9A channelopathy causes congenital inability to experience pain. Nature 444, 894-898. doi: 10.1038/nature05413

Cregg, R., Laguda, B., Werdehausen, R., Cox, J. J., Linley, J. E., Ramirez, J. D., et al. (2013). Novel mutations mapping to the fourth sodium channel domain of Nav1.7 result in variable clinical manifestations of primary erythromelalgia. Neuromolecular Med. 15, 265-278. doi: 10.1007/s12017-0128216-8

Cummins, T. R., Howe, J. R., and Waxman, S. G. (1998). Slow closed-state inactivation: a novel mechanism underlying ramp currents in cells expressing the hNE/PN1 sodium channel. J. Neurosci. 18, 9607-9619.

Dib-Hajj, S. D., Cummins, T. R., Black, J. A., and Waxman, S. G. (2007). From genes to pain: Na v 1.7 and human pain disorders. Trends Neurosci. 30, 555-563. doi: 10.1016/j.tins.2007.08.004

Drenth, J. P., and Michiels, J. J. (1990). Three types of erythromelalgia. BMJ 301, 985-986. doi: 10.1136/bmj.301.6758.985-c 
Estacion, M., Yang, Y., Dib-Hajj, S. D., Tyrrell, L., Lin, Z., Yang, Y., et al. (2013). A new Nav1.7 mutation in an erythromelalgia patient. Biochem. Biophys. Res. Commun. 432, 99-104. doi: 10.1016/j.bbrc.2013.01.079

Ge, J., Sun, A., Paajanen, V., Wang, S., Su, C., Yang, Z., et al. (2008). Molecular and clinical characterization of a novel SCN5A mutation associated with atrioventricular block and dilated cardiomyopathy. Circ. Arrhythm. Electrophysiol. 1, 83-92. doi: 10.1161/CIRCEP.107.750752

Goldin, A. L., Barchi, R. L., Caldwell, J. H., Hofmann, F., Howe, J. R., Hunter, J. C., et al. (2000). Nomenclature of voltage-gated sodium channels. Neuron 28 , 365-368. doi: 10.1016/S0896-6273(00)00116-1

Gosselin-Badaroudine, P., Keller, D. I., Huang, H., Pouliot, V., Chatelier, A., Osswald, S., et al. (2012). A proton leak current through the cardiac sodium channel is linked to mixed arrhythmia and the dilated cardiomyopathy phenotype. PLoS ONE 7:e38331. doi: 10.1371/journal.pone.00 38331

Haas, J., Frese, K. S., Peil, B., Kloos, W., Keller, A., Nietsch, R., et al. (2014). Atlas of the clinical genetics of human dilated cardiomyopathy. Eur. Heart J. doi: 10.1093/eurheartj/ehu301. [Epub ahead of print].

Isom, L. L. (2001). Sodium channel beta subunits: anything but auxiliary. Neuroscientist 7, 42-54. doi: 10.1177/107385840100700108

Jurkat-Rott, K., Holzherr, B., Fauler, M., and Lehmann-Horn, F. (2010). Sodium channelopathies of skeletal muscle result from gain or loss of function. Pflugers Arch. 460, 239-248. doi: 10.1007/s00424-010-0814-4

Kokunai, Y., Goto, K., Kubota, T., Fukuoka, T., Sakoda, S., Ibi, T., et al. (2012). A sodium channel myotonia due to a novel SCN4A mutation accompanied by acquired autoimmune myasthenia gravis. Neurosci. Lett. 519, 67-72. doi: 10.1016/j.neulet.2012.05.023

Laedermann, C. J., Cachemaille, M., Kirschmann, G., Pertin, M., Gosselin, R. D., Chang, I., et al. (2013). Dysregulation of voltage-gated sodium channels by ubiquitin ligase NEDD4-2 in neuropathic pain. J. Clin. Invest. 123, 3002-3013. doi: 10.1172/JCI68996

Laedermann, C. J., Syam, N., Pertin, M., Decosterd, I., and Abriel, H. (2013). Beta1and beta3- voltage-gated sodium channel subunits modulate cell surface expression and glycosylation of Nav1.7 in HEK293 cells. Front. Cell. Neurosci. 7:137. doi: 10.3389/fncel.2013.00137

Laurent, G., Saal, S., Amarouch, M. Y., Beziau, D. M., Marsman, R. F., Faivre, L., et al. (2012). Multifocal ectopic Purkinje-related premature contractions: a new SCN5A-related cardiac channelopathy. J. Am. Coll. Cardiol. 60, 144-156. doi: 10.1016/j.jacc.2012.02.052

Lee, M. J., Yu, H. S., Hsieh, S. T., Stephenson, D. A., Lu, C. J., and Yang, C. C. (2007). Characterization of a familial case with primary erythromelalgia from Taiwan. J. Neurol. 254, 210-214. doi: 10.1007/s00415-006-0328-3

Liu, M., Yang, K.-C., and Dudley, S. C. Jr. (2014). Cardiac sodium channel mutations: why so many phenotypes? Nat. Rev. Cardiol. 11, 607-615. doi: 10.1038/nrcardio.2014.85

Maier, S. K., Westenbroek, R. E., McCormick, K. A., Curtis, R., Scheuer, T., and Catterall, W. A. (2004). Distinct subcellular localization of different sodium channel alpha and beta subunits in single ventricular myocytes from mouse heart. Circulation 109, 1421-1427. doi: 10.1161/01.CIR.0000121421.61 896.24

Maier, S. K., Westenbroek, R. E., Schenkman, K. A., Feigl, E. O., Scheuer, T., and Catterall, W. A. (2002). An unexpected role for brain-type sodium channels in coupling of cell surface depolarization to contraction in the heart. Proc. Natl. Acad. Sci. U.S.A. 99, 4073-4078. doi: 10.1073/pnas.261705699

Mann, S. A., Castro, M. L., Ohanian, M., Guo, G., Zodgekar, P., Sheu, A., et al. (2012). R222Q SCN5A mutation is associated with reversible ventricular ectopy and dilated cardiomyopathy. J. Am. Coll. Cardiol. 60, 1566-1573. doi: 10.1016/j.jacc.2012.05.050

McNair, W. P., Ku, L., Taylor, M. R., Fain, P. R., Dao, D., Wolfel, E., et al. (2004). SCN5A mutation associated with dilated cardiomyopathy, conduction disorder, and arrhythmia. Circulation 110, 2163-2167. doi: 10.1161/01.CIR.0000144458.58660.BB

Meisler, M. H., O’Brien, J. E., and Sharkey, L. M. (2010). Sodium channel gene family: epilepsy mutations, gene interactions and modifier effects. J. Physiol. 588(Pt 11), 1841-1848. doi: 10.1113/jphysiol.2010.188482

Morales, A., Painter, T., Li, R., Siegfried, J. D., Li, D., Norton, N., et al. (2010) Rare variant mutations in pregnancy-associated or peripartum cardiomyopathy. Circulation 121, 2176-2182. doi: 10.1161/CIRCULATIONAHA.109. 931220
Nair, K., Pekhletski, R., Harris, L., Care, M., Morel, C., Farid, T., et al. (2012). Escape capture bigeminy: phenotypic marker of cardiac sodium channel voltage sensor mutation R222Q. Heart Rhythm 9, 1681-1688 el. doi: 10.1016/j.hrthm.2012.06.029

Nguyen, T. P., Wang, D. W., Rhodes, T. H., and George, A. L. Jr. (2008). Divergent biophysical defects caused by mutant sodium channels in dilated cardiomyopathy with arrhythmia. Circ. Res. 102, 364-371. doi: 10.1161/CIRCRESAHA.107.164673

Noda, M., Shimizu, S., Tanabe, T., Takai, T., Kayano, T., Ikeda, T., et al. (1984). Primary structure of Electrophorus electricus sodium channel deduced from cDNA sequence. Nature 312, 121-127. doi: 10.1038/312 $121 \mathrm{a} 0$

Olson, T. M., Michels, V. V., Ballew, J. D., Reyna, S. P., Karst, M. L., Herron, K. J., et al. (2005). Sodium channel mutations and susceptibility to heart failure and atrial fibrillation. JAMA 293, 447-454. doi: 10.1001/jama.293.4.447

Payandeh, J., Scheuer, T., Zheng, N., and Catterall, W. A. (2011). The crystal structure of a voltage-gated sodium channel. Nature 475, 353-358. doi: 10.1038/nature10238

Petitprez, S., Tiab, L., Chen, L., Kappeler, L., Rosler, K. M., Schorderet, D., et al. (2008). A novel dominant mutation of the Nav1.4 alpha-subunit domain I leading to sodium channel myotonia. Neurology 71, 1669-1675. doi: 10.1212/01.wnl.0000335168.86248.55

Probst, V., Wilde, A. A., Barc, J., Sacher, F., Babuty, D., Mabo, P., et al. (2009). SCN5A mutations and the role of genetic background in the pathophysiology of Brugada syndrome. Circ. Cardiovasc. Genet. 2, 552-557. doi: 10.1161/CIRCGENETICS.109.853374

Rush, A. M., Cummins, T. R., and Waxman, S. G. (2007). Multiple sodium channels and their roles in electrogenesis within dorsal root ganglion neurons. J. Physiol. 579(Pt 1), 1-14. doi: 10.1113/jphysiol.2006.121483

Sangameswaran, L., Fish, L. M., Koch, B. D., Rabert, D. K., Delgado, S. G., Ilnicka, M., et al. (1997). A novel tetrodotoxin-sensitive, voltage-gated sodium channel expressed in rat and human dorsal root ganglia. J. Biol. Chem. 272, 14805-14809. doi: 10.1074/jbc.272.23.14805

Shen, C., Xu, L., Yang, Z., Zou, Y., Hu, K., Fan, Z., et al. (2013). A1180V of cardiac sodium channel gene (SCN5A): is it a risk factor for dilated cardiomyopathy or just a common variant in Han Chinese? Dis. Markers 35, 531-535. doi: $10.1155 / 2013 / 659528$

Shy, D., Gillet, L., and Abriel, H. (2013). Cardiac sodium channel NaV1.5 distribution in myocytes via interacting proteins: the multiple pool model. Biochim. Biophys. Acta 1833, 886-894. doi: 10.1016/j.bbamcr.2012. 10.026

Shy, D., Gillet, L., Ogrodnik, J., Albesa, M., Verkerk, A. O., Wolswinkel, R., et al. (2014). PDZ domain-binding motif regulates cardiomyocyte compartmentspecific NaV1.5 channel expression and function. Circulation 130, 147-160. doi: 10.1161/CIRCULATIONAHA.113.007852

Sokolov, S., Scheuer, T., and Catterall, W. A. (2007). Gating pore current in an inherited ion channelopathy. Nature 446, 76-78. doi: 10.1038/nature05598

Swan, H., Amarouch, M. Y., Leinonen, J., Marjamaa, A., Kucera, J. P., LaitinenForsblom, P. J., et al. (2014). Gain-of-function mutation of the SCN5A gene causes exercise-induced polymorphic ventricular arrhythmias. Circ. Cardiovasc. Genet. 7, 771-781. doi: 10.1161/CIRCGENETICS.114.000703

Toledo-Aral, J. J., Moss, B. L., He, Z. J., Koszowski, A. G., Whisenand, T., Levinson, S. R., et al. (1997). Identification of PN1, a predominant voltage-dependent sodium channel expressed principally in peripheral neurons. Proc. Natl. Acad. Sci. U.S.A. 94, 1527-1532. doi: 10.1073/pnas.94.4.1527

Vasylyev, D. V., Han, C., Zhao, P., Dib-Hajj, S., and Waxman, S. G. (2014). Dynamic-clamp analysis of wild-type human Nav1.7 and erythromelalgia mutant channel L858H. J. Neurophysiol. 111, 1429-1443. doi: 10.1152/jn.00763.2013

Wagner, S., Lerche, H., Mitrovic, N., Heine, R., George, A. L., and Lehmann-Horn, F. (1997). A novel sodium channel mutation causing a hyperkalemic paralytic and paramyotonic syndrome with variable clinical expressivity. Neurology 49, 1018-1025. doi: 10.1212/WNL.49.4.1018

Yang, T., Atack, T. C., Stroud, D. M., Zhang, W., Hall, L., and Roden, D. M. (2012). Blocking Scn10a channels in heart reduces late sodium current and is antiarrhythmic. Circ. Res. 111, 322-332. doi: 10.1161/CIRCRESAHA.112. 265173

Yoshinaga, H., Sakoda, S., Good, J. M., Takahashi, M. P., Kubota, T., ArikawaHirasawa, E., et al. (2012). A novel mutation in SCN4A causes severe myotonia 
and school-age-onset paralytic episodes. J. Neurol. Sci. 315, 15-19. doi: 10.1016/j.jns.2011.12.015

Yu, F. H., and Catterall, W. A. (2003). Overview of the voltage-gated sodium channel family. Genome Biol. 4:207. doi: 10.1186/gb-2003-4-3-207

Conflict of Interest Statement: The authors declare that the research was conducted in the absence of any commercial or financial relationships that could be construed as a potential conflict of interest.

Received: 25 November 2014; accepted: 30 January 2015; published online: 17 February 2015.
Citation: Amarouch M-Y and Abriel H (2015) Cellular hyper-excitability caused by mutations that alter the activation process of voltage-gated sodium channels. Front. Physiol. 6:45. doi: 10.3389/fphys.2015.00045

This article was submitted to Membrane Physiology and Membrane Biophysics, a section of the journal Frontiers in Physiology.

Copyright (c) 2015 Amarouch and Abriel. This is an open-access article distributed under the terms of the Creative Commons Attribution License (CC BY). The use, distribution or reproduction in other forums is permitted, provided the original author(s) or licensor are credited and that the original publication in this journal is cited, in accordance with accepted academic practice. No use, distribution or reproduction is permitted which does not comply with these terms. 